\title{
Essential oils of green cumin and chamomile partially protect against acute acetaminophen hepatotoxicity in rats
}

\author{
MOHAMED E. EBADA \\ Chronic Toxicity Branch, Department of Pharmacology, National Organization for Drug Control \\ and Research/ NODCAR, 51 Wezaret Elzeraa Street, 12654 Agouza, Giza, Egypt
}

Manuscript received on October 16, 2017; accepted for publication on February 5, 2018

\begin{abstract}
Essential oils of green cumin (Cuminum cyminum) and chamomile (Chamomilla recutita) have antioxidant and anti-inflammatory effects. Acetaminophen, $N$-acetyl- $p$-amino-phenol, is an over-the-counter analgesic and antipyretic. Despite being safe at therapeutic doses, acetaminophen overdose is a leading cause of acute liver failure. This study aimed to compare the possible protective effects of cumin and chamomile essential oils against acute acetaminophen hepatotoxicity in male rats. Cumin oil $(400 \mathrm{mg} / \mathrm{kg})$ and chamomile oil $(250 \mathrm{mg} / \mathrm{kg})$ were orally administered for 2 weeks prior to a single acetaminophen dose $(1 \mathrm{~g} / \mathrm{kg})$. Serum liver function enzymes, oxidative stress markers in the liver and histopathological features were evaluated. Acetaminophen caused marked damage to hepatocytes evidenced by a significant rise in the levels of liver function enzymes, including alanine aminotransferase and aspartate aminotransferase, and disruption to the liver antioxidant protective system. Whereas the cumin oil normalized acetaminophen-induced liver enzymes elevation, the chamomile oil slightly attenuated the increase in alanine aminotransferase levels in acetaminophen-intoxicated rats. The Chamomile oil moderately ameliorated glutathione depletion and the decrease in superoxide dismutase activity in the liver of acetaminophen-administered rats. The Cumin oil preserved the liver structure to a greater extent than chamomile oil in acetaminophen-intoxicated rats. Essential oils of cumin and chamomile partially counteracted acute acetaminophen hepatotoxicity.
\end{abstract}

Key words: Acetaminophen, acute hepatotoxicity, chamomile, Cuminum cyminum, histopathology.

\section{INTRODUCTION}

Acetaminophen (APAP) has been widely used as an over-the-counter analgesic and antipyretic (Leung 2012). Clinically, APAP's daily dosage should not exceed $4 \mathrm{~g}$ in divided doses according to British National Formulary 70 (Royal Pharmaceutical

E-mail: drmohamedebada36@gmail.com

* Contribution to the centenary of the Brazilian Academy of Sciences.
Society 2015). Despite being generally safe at its therapeutic levels, lower APAP doses for geriatric patients with insufficient liver function and accurate APAP doses for pediatric patients are highly recommended to avoid APAP-induced liver injury (Royal Pharmaceutical Society 2015). APAP hepatotoxicity has been a leading cause of acute liver failure and could necessitate liver transplantation (Lee 2013, Woolbright and Jaeschke 2016). APAP at toxic plasma levels has been found to induce a 
state of oxidative stress featuring marked depletion of reduced glutathione (GSH), propagation of lipid peroxidation and substantial distortion to hepatic antioxidant enzymes (El Morsy and Kamel 2015, Ghanem et al. 2016). Upon exposure to APAP overdose, decreased liver GSH content renders hepatocytes highly exposed to APAP's reactive metabolite $N$-acetyl- $p$-benzoquinone-imine, generated by cytochrome P450 metabolizing enzymes, i.e. mainly CYP2E1 (Gonzalez 2007), resulting in liver injury with a subsequent increase in the serum levels of liver rich enzymes such as alanine aminotransferase (ALT) and aspartate aminotransferase (AST) (El Morsy and Kamel 2015, Ghanem et al. 2016). In experimental animals, APAP toxicity is associated with overproduction of reactive oxygen species such as superoxide anions (Woolbright and Jaeschke 2016), removed by superoxide dismutase (SOD), which aggressively attack hepatocytes resulting in marked congestion in the central vein, inflammation, hepatocellular degeneration and necrosis (Xie et al. 2016). On the other hand, SH-donating compounds such as $\mathrm{N}$-acetylcysteine are effective antidotes against APAP hepatotoxicity (Kisaoglu et al. 2014).

APAP overdose has been repeatedly implemented as a model of drug-induced liver injury to investigate antioxidant/hepatoprotective effects of compounds of natural origin (E1 Morsy and Kamel 2015, Hasanein and Sharifi 2017, Kumari and Kakkar 2012, Xie et al. 2016). Given their popular use and relative safety profiles, the use of herbal remedies has been encouraged as a prophylactic approach to safeguard against oxidative-distress implicated pathologies such as drug-induced liver injury (Madrigal-Santillan et al. 2014, Singh et al. 2016) and malignancies (Miyanishi et al. 2015). Green cumin (Cuminum cyminum L., Umbelliferae) (Mnif and Aifa 2015) and chamomile (Chamomilla recutita L., Compositae) (Srivastava et al. 2010) are preferably consumed for their spicy taste, mainly cumin, and their multiple therapeutic benefits. The chamomile essential oil (CHEO) possesses anti-inflammatory, antioxidant and anticancer effects (AgatonovicKustrin et al. 2015, McKay and Blumberg 2006). Major constituents in CHEO including $\alpha$-bisabolol and chamazulene have been found to mediate such medical effects (Cavalieri et al. 2011, Flemming et al. 2015, Rocha et al. 2011). In addition, CHEO's sesquiterpenoid trans- $\beta$-farnesene content was reported to possess hepatoprotective effects (Vinholes et al. 2014). On the other hand, the cumin essential oil (CUEO) contains around 30 components and it has antioxidant, antineoplastic, antibacterial, anti-inflammatory and hypoglycemic effects (Allahghadri et al. 2010, Patil et al. 2013, Wei et al. 2015). Major ingredients in CUEO such as cuminaldehyde, $\alpha$-pinene and $\gamma$-terpinene contribute to its anti-inflammatory and antioxidant properties (Chen et al. 2014, Rufino et al. 2014, Tomy et al. 2014). Two previous studies, evaluating biochemical alterations and/or selected markers of oxidative stress, reported complete protective effects mediated by the whole Cuminum cyminum seeds against hepatotoxicity induced by chronic APAP administration (Elhabib et al. 2007), and by the Chamomilla recutita extract against acute acetaminophen hepatotoxicity (Gupta and Misra 2006). However, those studies showed certain limitations such as unequal dosing between animals, being APAP or cumin seeds mixed with diet/drinking water in one study (Elhabib et al. 2007), and the administration of a very small and single APAP dose $(200 \mathrm{mg} / \mathrm{kg})$ to rats in another study (Gupta and Misra 2006). It has been well documented that $1 \mathrm{~g} / \mathrm{kgAPAP}$ is the highest tolerable dose in rats (Jin et al. 2012) and, therefore, the acute oral APAP dose required to produce considerable liver injury in rats has been found to be $1 \mathrm{~g} / \mathrm{kg}$ or more in most studies (El Morsy and Kamel 2015, Kiran et al. 2012). Other limitations were the lack of the liver histopathological examination in the chamomile's study (Gupta and Misra 2006) and 
the absence of evaluating the impact on the liver antioxidant protective system in the cumin's study (Elhabib et al. 2007). It has been suggested that marked elevation of liver enzymes is not always associated with severe liver injury or impaired liver antioxidant system (Contreras-Zentella and Hernández-Muñoz 2016). Generally, biochemical alterations, histological features and markers of oxidative stress are essentially evaluated to judge potential hepatoprotective effects. The present work aimed to compare the possible hepatoprotective impact of CUEO and CHEO administered for 2 weeks prior to a single acetaminophen toxic dose $(1 \mathrm{~g} / \mathrm{kg}$ body weight $)$ in male rats.

\section{MATERIALS AND METHODS}

\section{CHEMICALS}

APAP was purchased from El-Nasr Pharmaceutical Company (Cairo, Egypt). Tween 80, GSH, (Ellman's reagent) or 5,5'-dithiobis(2-nitrobenzoic acid), trichloroacetic acid, thiobarbituric acid and 1,1,3,3-tetramethoxypropane, Tris(hydroxymethyl) aminomethane, diethylenetriaminepentaacetic acid, pyrogallol and SOD were purchased from SigmaAldrich. All other chemicals were of standard analytical grade.

\section{ESSENTIAL OILS}

CUEO and CHEO were generously obtained from an Egyptian company, Hashem Brothers for Essential Oils and Aromatic Products. According to the manufacturer's certificate of analysis (Analysis S1 - Supplementary Material), CHEO mainly contained trans- $\beta$-farnesene, $\alpha$-bisabolol oxide A, $\alpha$-bisabolol B and chamazulene. On the other hand, major components in CUEO were $\mathrm{y}$-terpinene, cuminaldehyde, $\alpha$-pinene and $\beta$-pinene (Analysis S2 - Supplementary Material).

\section{ANIMALS}

Twenty four adult male Wistar rats weighing 180$200 \mathrm{~g}$ were obtained from the Holding Company for Biological Products and Vaccines (VACSERA), Egypt. The animals were kept under controlled laboratory conditions of ventilation/humidity and 12:12 light/dark cycle throughout the period of the study. Rats were housed in groups of 3 and were provided with free access to standard diet and water. All experiments were carried out in accordance with the UK Animal Scientific Procedures Act 1986 and approved guidelines set for animal care and use at National Organization for Drug Control and Research (NODCAR), Giza, Egypt.

\section{EXPERIMENTAL DESIGN}

After one week of acclimatization, rats were assigned to 4 groups $(\mathrm{n}=6)$. For 14 days (Treatment I), groups I (control) and II (toxic) received the vehicle of essential oils ( $1 \%$ Tween 80 in distilled water), and groups III and IV received CUEO (400 mg/kg/day) and CHEO (250 mg/kg/ day), respectively (Al-Musa and AL-Hashem 2014, Jagtap and Patil 2010). Tween 80 at 1\% was used as a solubilizing agent to aid diluting concentrated essential oils, and it was reported that repeated oral administration of more concentrated Tween 80 solution (up to $10 \%$ ) for 2 weeks was not associated with liver injury (E1 Morsy and Kamel 2015). The CHEO dose was selected based on previous studies demonstrating that treating rats for 4 weeks with increasing doses $(\leq 500 \mathrm{mg} / \mathrm{kg} /$ day) of the Chamomile recutita extract did not cause significant toxicity (Al-Musa and AL-Hashem 2014). On the other hand, the CUEO dose used in the present study was found to improve pancreatic antioxidant enzymes in diabetic rats (Jagtap and Patil 2010). On Day 13, rats had no access to food for 18 hours (El Morsy and Kamel 2015), as fasting may potentiate APAP hepatotoxicity (Whitcomb and Block 1994). On Day 14, APAP 
$1 \mathrm{~g} / \mathrm{kg}$ (Treatment II), suspended in $1 \%$ sodium carboxymethylcellulose, was administered to rats in groups II-IV (Gunduz et al. 2015, Jin et al. 2012), one hour after Treatment I's fourteenth dose. APAP and essential oils were freshly prepared and their concentrations were adjusted so that each $100 \mathrm{~g}$ animal body weight received $0.5 \mathrm{ml}$ solution. All treatments were orally administered.

BLOOD AND LIVER SAMPLING

Twenty four hours after APAP administration, blood samples were collected into non-heparinized tubes, permitting blood coagulation and serum separation, by puncturing the retro-orbital venous plexus (Sorg and Buckner 1964), and were left for 1 hour at the room temperature before being centrifuged at 3000 rpm for $20 \mathrm{~min}$ for serum collection. Rats were euthanized, and livers were rapidly dissected and rinsed with ice cooled saline $(0.9 \% \mathrm{NaCl})$. Liver specimens were fixed in $10 \%$ neutral buffered formalin for histological examination. The liver tissue remainder and sera were kept at $-80{ }^{\circ} \mathrm{C}$ for further analysis.

\section{BIOCHEMICAL ASSAYS}

Colorimetric assay kits (Biolabo, France) were used to measure serum levels of ALT and AST (Reitman and Frankel 1957). Also, serum levels of alkaline phosphatase, ALP, (QCA, Spain) and total protein (Stanbio, USA) were determined using colorimetric assay kits (Klein et al. 1960, Weichselbaum 1946).

DETERMINATION OF MARKERS OF OXIDATIVE STRESS IN THE RAT LIVERS

The frozen liver tissues were left at room temperature for thawing, weighed and homogenized into ice-cooled $1.17 \% \mathrm{KCl}$ solution ( $\mathrm{pH}$ adjusted to be 7.4 by adding $\mathrm{K}_{2} \mathrm{HPO}_{4}$ and $\left.\mathrm{KH}_{2} \mathrm{PO}_{4}\right)$ to prepare $10 \%(\mathrm{w} / \mathrm{v})$ homogenates. The liver homogenate was divided into three aliquots. The first part was used for the estimation of the liver GSH content (Ahmed et al. 1991). Briefly, equal volumes of the homogenate and the ice-cold precipitating solution $(12 \%$ trichloroacetic acid + $6 \mathrm{mM}$ EDTA) were vortex-mixed and centrifuged at $3000 \mathrm{rpm}$ for 5 minutes. Then, the supernatant was treated with Ellman's reagent dissolved in 1\% sodium citrate, and the absorbance was measured spectrophotometrically at $412 \mathrm{~nm}$. The second aliquot was centrifuged at $3000 \mathrm{rpm}$ for 15 minutes and the supernatant was used for the determination of the total protein (Weichselbaum 1946) and the lipid peroxidation degradation product malondialdehyde (MDA) levels (Uchiyama and Mihara 1978). The supernatant was mixed with $1 \%$ orthophosphoric acid $(\mathrm{pH} \sim 2)$ and $0.6 \%$ thiobarbituric acid, and the mixture was firstly heated in a boiling water bath for 45 minutes, and was later left to cool at the room temperature before being mixed well with n-butanol. The absorbance of the separated n-butanol layer, containing a pink colored substance formed as a result of the reaction between MDA and thiobarbituric acid, was measured at $520 \mathrm{~nm}$ and $535 \mathrm{~nm}$, and the difference between the two readings corresponded to MDA levels. The third aliquot was centrifuged at $85,000 \mathrm{rpm}$ for 15 minutes at $4{ }^{\circ} \mathrm{C}$ and the supernatant was used for the determination of cytosolic SOD activity (Marklund and Marklund 1974). One unit of SOD was defined as its amount which inhibits $50 \%$ of pyrogallol autoxidation. In the cuvette, $0.2 \mathrm{mM}$ pyrogallol and Tris $\mathrm{HCl}$ buffer $(\mathrm{pH}=8.2)$, containing 50 $\mathrm{mM}$ Tris(hydroxymethyl)aminomethane, $1 \mathrm{mM}$ diethylenetriaminepentaacetic acid and $200 \mathrm{mM}$ $\mathrm{HCl}$, were added to $10 \mu \mathrm{l}$ sample. The absorbance of the mixture was measured at $420 \mathrm{~nm}$ every minute for 2 minutes, and the difference between the two readings accounted for SOD activity. Following the same procedures, 1,1,3,3-tetramethoxypropane, standard GSH and SOD were used to generate standard curves for the determination of MDA and GSH levels and SOD activity, respectively. Levels of GSH (mg) and MDA (nmol) were expressed 
relative to $\mathrm{mg}$ protein and SOD activity was expressed as $\mathrm{U} / \mathrm{min} / \mathrm{mg}$ protein.

\section{HISTOPATHOLOGICAL EXAMINATION}

Twenty four hours after necropsy, formalin preserved liver specimens were left under running water overnight to wash off the fixative. Fixed tissues were dehydrated with a graded series of alcohols before being cleared in methyl benzoate and embedded in paraffin. Later, $3 \mu \mathrm{M}$ thick sections were cut by a microtome, and were stained with hematoxylin and counter stained with eosin (Gabe 1968). Dry sections were examined under the optical microscope and representative images were captured using a digital camera attached to the microscope. Five histopathological features (necrosis, inflammatory cells infiltration, degeneration, central vein congestion and hemorrhage) were evaluated and scored in each group (Lobenhofer et al. 2006).

\section{STATISTICAL ANALYSIS}

Data are expressed as mean \pm SEM and were analyzed using one way analysis of variance (ANOVA) followed by post-hoc Tukey's test for multiple comparisons. Also, the percent change of each group relative to the control group was calculated for all variables. IBM SPSS package version 19 was used to perform statistical analyses, and significance was considered when $p$ was $<0.05$.

\section{RESULTS}

EFFECTS OF 14-DAY TREATMENT WITH CUEO OR CHEO ON ACUTE APAP-INDUCED ELEVATION OF LIVER FUNCTION ENZYMES

One way ANOVAs revealed significant differences between groups in serum levels of ALT $[\mathrm{F}(3.20)=17.60 ; \mathrm{p}<0.001]$ and $\operatorname{AST}[\mathrm{F}(3.20)=11.64$; $\mathrm{p}<0.001]$. Tukey's post-hoc tests detected that rats treated only with APAP in the toxic group exhibited a significant rise in the serum levels of ALT $(p<0.001)$ and AST ( $\mathrm{p}=0.006)$, compared to the control group
(Figure 1). In contrast, CUEO markedly attenuated APAP-induced rise in ALT $(\mathrm{p}<0.001)$ and AST $(\mathrm{p}=0.002)$. To lesser extent, CHEO decreased ALT levels $(\mathrm{p}=0.024)$ in APAP-treated rats (Figure 1). Clearly, there were no significant effects of CHEO on AST levels $(\mathrm{p}=0.98)$ in APAP-administered rats. CUEO reduced serum levels of ALT $(p=0.049)$ and AST $(p=0.001)$ to a greater extent than CHEO in APAP-intoxicated rats. The percent change in serum ALT and AST levels, relative to control, for each group is indicated above the relevant bars.

Also, results revealed that the serum levels of ALP $[\mathrm{F}(3.20)=2.10 ; \mathrm{p}=0.13]$ and total protein $[F(3.20)=2.22 ; p=0.12]$ did not differ between groups (Table I).

\section{EFFECTS OF REPEATED ADMINISTRATION OF CUEO OR CHEO ON SELECTED MARKERS OF OXIDATIVE STRESS INDUCED BY A SINGLE APAP DOSE IN THE RAT LIVER}

Oxidative stress in the liver was statistically detected among all APAP-administered groups, evidenced by significant changes in the liver content of GSH $[\mathrm{F}(3.20)=5.52 ; \mathrm{p}=0.006]$ and $\operatorname{MDA}[\mathrm{F}(3.20)=8.24$; $\mathrm{p}=0.001]$ as well as the liver SOD activity $[F(3.20)=4.17 ; p=0.019]$. Whereas a significant drop in the liver GSH levels of rats treated only with APAP ( $p=0.013)$ or with APAP and CUEO ( $p$ $=0.011)$ was reported, CHEO treatment moderately ameliorated the liver GSH depletion in APAPintoxicated rats $(p=0.37)$, compared to the control group. The percent change in the liver GSH levels of each group relative to control is mentioned in Table II. On the other hand, all APAP-treated groups showed a significant rise in the liver MDA levels compared to the control group (Toxic, $\mathrm{p}=0.049$, CUEO+APAP and CHEO+APAP, $p=0.002)$. Consequently, the percent changes in the liver MDA levels of APAP-treated groups relative to control were as follows: Toxic (92.64\%), CUEO+APAP (141.86\%) and CHEO+APAP (142.45\%). Similar to its effect on the liver GSH content, acute APAP 
a

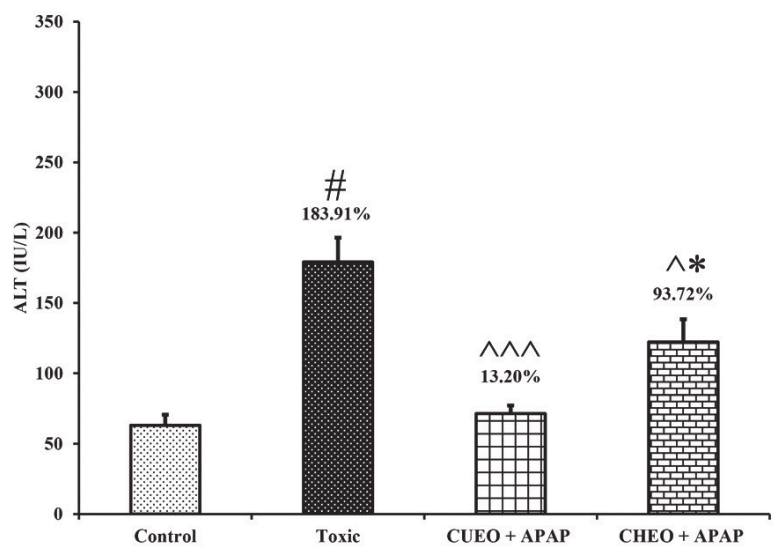

$\mathrm{b}$

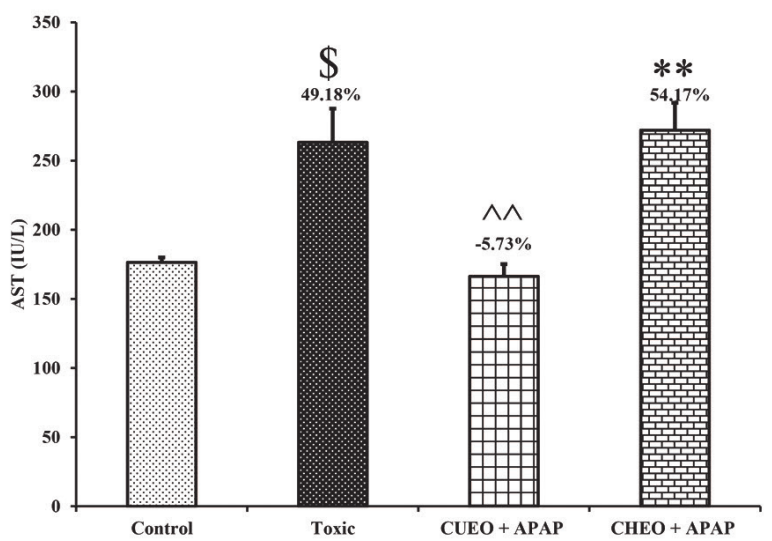

Figure 1 - Effects of 2-week treatment with CUEO or CHEO on serum ALT (a) and AST (b) levels 24 hours after acute APAP administration. Control $=1 \%$ Tween 80 (p.o. for 14 days), Toxic $=1 \%$ Tween 80 (p.o. for 14 days) and APAP (acetaminophen: $1 \mathrm{~g} / \mathrm{kg}$, p.o. on Day 14), CUEO = cumin essential oil (400 mg/kg/day, p.o. for 14 days), CHEO = chamomile essential oil (250 mg/ $\mathrm{kg}$ /day, p.o. for 14 days). ${ }^{\mathrm{S}} \mathrm{p}<0.01,{ }^{\#} \mathrm{p}<0.001$ compared to Control; ${ }^{\wedge} \mathrm{p}<0.05,{ }^{\wedge} \mathrm{p}<0.01,{ }^{\wedge} \mathrm{p}<0.001$ compared to Toxic; ${ }^{*} \mathrm{p}<0.05$, ${ }^{* *} \mathrm{p}<0.01$ compared to CUEO + APAP \% change is indicated on bars relative to control.

TABLE I

Effects of 2-week treatment with CUEO or CHEO on serum levels of ALP and total protein in APAP-intoxicated rats.

\begin{tabular}{ccc}
\hline Groups & ALP $(\mathrm{U} / \mathrm{L})$ & Total Protein $(\mathrm{g} / \mathrm{dl})$ \\
\hline Group I & $207.55 \pm 13.74$ & $5.89 \pm 0.23$ \\
(Control) & & \\
Group II & $175.11 \pm 8.07$ & $6.60 \pm 0.15$ \\
(Toxic) & $(-15.63 \%)$ & $(12.02 \%)$ \\
Group III & $174.08 \pm 13.00$ & $6.21 \pm 0.19$ \\
(CUEO+APAP) & $(-16.13 \%)$ & $(5.48 \%)$ \\
Group IV & $193.92 \pm 8.38$ & $6.13 \pm 0.21$ \\
(CHEO+APAP) & $(-6.57 \%)$ & $(3.98 \%)$ \\
\hline
\end{tabular}

Data are presented as mean \pm SEM. No significant differences $(p>0.05)$ in serum levels of ALP and total protein were reported. The percent change relative to control is highlighted in brackets. Control $=1 \%$ Tween 80 (p.o. for 14 days), Toxic $=$ $1 \%$ Tween 80 (p.o. for 14 days) and APAP (acetaminophen: 1g/ kg, p.o. on Day 14, twenty-four hours before blood sampling and liver dissection), CUEO = cumin essential oil $(400 \mathrm{mg} / \mathrm{kg} /$ day, p.o. for 14 days $),$ CHEO = chamomile essential oil $(250$ $\mathrm{mg} / \mathrm{kg} /$ day, p.o. for 14 days). ALP = alkaline phosphatase.

administration caused a significant decrease in the liver SOD activity in the toxic group $(\mathrm{p}=0.03)$ and CUEO+APAP treated rats $(\mathrm{p}=0.044)$, but not in $\mathrm{CHEO}+\mathrm{APAP}$ treated rats $(\mathrm{p}=0.62)$, compared to the control group. Whereas $\%$ change in the liver
SOD activity was substantially high for rats treated solely with APAP $(106.72 \%)$ or with CUEO+APAP $(100.16 \%)$, CHEO+APAP treated rats exhibited only $42.99 \%$ reduction in the liver SOD activity relative to the control.

\section{IMPACT OF 2-WEEK TREATMENT WITH CUEO \\ OR CHEO ON ACUTE APAP-INDUCED LIVER HISTOPATHOLOGY}

Microscopic examination revealed normal pattern of hepatocytes in the control rats. In contrast, acute APAP treatment caused massive degeneration and necrosis to hepatocytes, central vein congestion, hemorrhage and infiltration of nonspecific inflammatory cells between hepatocytes. On the other hand, CUEO moderately preserved the liver structure by limiting the necrosis of hepatocytes and by mitigating the migration of inflammatory cells between hepatocytes to a greater extent than CHEO in APAP-intoxicated rats; Figure 2a-d illustrates representative microscopic images of the rat liver for all groups (I-IV). The five observed criteria of the histopathological evaluation were scored to describe the magnitude of the liver injury as appropriate (Table III). 


\section{DISCUSSION}

The present study demonstrated that repeated treatment with CUEO or CHEO partially counteracted acute APAP-induced liver injury in rats. Whereas CUEO markedly reduced the elevated serum levels of ALT and AST, CHEO moderately ameliorated GSH depletion and reduced SOD activity in APAP-intoxicated rats. Essential oils of green cumin and chamomile failed to suppress MDA generation, although the histopathological features associated with acute APAP hepatotoxicity were alleviated to a greater extent by prior CUEO treatment.

As stated earlier, acute APAP toxicity caused massive destruction to hepatocytes, resulting in elevation of serum ALT and AST levels, and induced a state of oxidative stress manifested by the accumulation of MDA, depletion of GSH and reduction of SOD activity in the liver. These findings were in agreement with a wide range of studies investigating potential hepatoprotective effects of herbal products against APAP hepatotoxicity (El Morsy and Kamel 2015, Hamza and Al-Harbi 2015, Xie et al. 2016). Previous research revealed that APAP hepatotoxicity was associated with diminished activity of liver antioxidant enzymes such as superoxide dismutase, glutathione reductase and glutathione peroxidase (El Morsy and Kamel 2015, Hamza and Al-Harbi 2015, Xie et al. 2016). There are three SOD isoforms, including copper/zinc SOD (cytosolic and major form) and manganese SOD (mitochondrial form). The third form is located in extracellular and nuclear compartments (Weydert and Cullen 2010).

TABLE II

Effects of repeated administration of CUEO or CHEO on key markers of oxidative stress in the rat liver after acute APAP toxicity.

\begin{tabular}{cccc}
\hline Groups & GSH (mg/mg protein) & MDA (nmol/mg protein) & SOD (U/min/mg protein) \\
\hline Group I (Control) & $1.49 \pm 0.20$ & $9.32 \pm 1.06$ & $5.95 \pm 1.20$ \\
Group II (Toxic) & $0.79 \pm 0.13^{\mathrm{a}}(-47.00 \%)$ & $17.95 \pm 2.80^{\mathrm{a}}(92.64 \%)$ & $12.30 \pm 2.10^{\mathrm{a}}(106.72 \%)$ \\
Group III (CUEO+APAP) & $0.77 \pm 0.08^{\mathrm{a}}(-48.16 \%)$ & $22.53 \pm 2.52^{\mathrm{b}}(141.86 \%)$ & $11.91 \pm 1.39^{\mathrm{a}}(100.16 \%)$ \\
Group IV (CHEO+APAP) & $1.15 \pm 0.14(-22.95 \%)$ & $22.59 \pm 1.90^{\mathrm{b}}(142.45 \%)$ & $8.51 \pm 0.95(42.99 \%)$ \\
\hline
\end{tabular}

Data are presented as mean \pm SEM. Statistical analysis revealed ${ }^{\mathrm{a}} \mathrm{p}<0.05,{ }^{\mathrm{b}} \mathrm{p}<0.01$ compared to control, \% Change relative to control is highlighted in brackets. Control $=1 \%$ Tween 80 (p.o. for 14 days), Toxic $=1 \%$ Tween 80 (p.o. for 14 days) and APAP (acetaminophen: $1 \mathrm{~g} / \mathrm{kg}$, p.o. on Day 14, twenty-four hours before blood sampling and liver dissection), CUEO = cumin essential oil $(400 \mathrm{mg} / \mathrm{kg}$ /day,p.o. for 14 days $), \mathrm{CHEO}=$ chamomile essential oil ( $250 \mathrm{mg} / \mathrm{kg} / \mathrm{day}$, p.o. for 14 days $) . \mathrm{GSH}=$ reduced glutathione, $\mathrm{MDA}=$ malondialdehyde, $\mathrm{SOD}=$ superoxide dismutase.

TABLE III

Impact of repeated CUEO or CHEO administration on histopathological features of acute APAP hepatotoxicity.

\begin{tabular}{ccccc}
\hline Observations & \multicolumn{5}{c}{ Groups } \\
\cline { 2 - 5 } & Control & Toxic & CUEO + APAP & CHEO + APAP \\
\hline Hepatocyte necrosis & 0 & +++ & + & ++ \\
Inflammation (cellular infiltration) & 0 & +++ & + & ++ \\
Degeneration & 0 & +++ & + & ++ \\
Dilated central vein & 0 & +++ & + & + \\
Hemorrhage & 0 & ++ & + \\
\hline
\end{tabular}

Control $=1 \%$ Tween 80 (p.o. for 14 days), Toxic $=1 \%$ Tween 80 (p.o. for 14 days) and APAP (acetaminophen: $1 \mathrm{~g} / \mathrm{kg}$, p.o. on Day 14 , twenty-four hours before blood sampling and liver dissection), CUEO = cumin essential oil (400 mg/kg/day, p.o. for 14 days), $\mathrm{CHEO}=$ chamomile essential oil $(250 \mathrm{mg} / \mathrm{kg} /$ day, .o. for 14 days $) .0=$ minimal, $+=$ mild,$++=$ moderate,$+++=$ marked. 
The activity of the liver manganese SOD in APAPintoxicated rats was reported to be higher than control rats 6 hours after APAP administration, but this initial rise in the manganese SOD activity dropped near the control level 24 hours after APAP exposure (Mladenovic et al. 2009). This suggests that acute APAP toxicity could rather temporarily activate the liver antioxidant defense system.

As mentioned earlier, previous studies undertaken by Gupta and Misra (2006) showed that the Chamomilla recutita extract $(400 \mathrm{mg} / \mathrm{kg}$, p.o., for 7 days) completely counteracted the increase in serum liver enzymes (ALT and AST) as well as the elevated MDA levels and the depleted glutathione content in the liver of rats sacrificed 48 hours after being treated with a single APAP dose (Gupta and Misra 2006). In fact, it was difficult to draw a definite conclusion about the hepatoprotective potential of the chamomile extract against APAP toxicity in the previous study owing to the small and single APAP dose administered to rats (200 $\mathrm{mg} / \mathrm{kg}$, p.o.), and the absence of histopathological studies and components analysis of the prepared chamomile extract (Gupta and Misra 2006). In another study, the chamomile flower extract, whose constituents were identified, received for 10 days, showed dose-dependent marked protection against liver injury induced by a single ethanol dose $(6 \mathrm{~g} / \mathrm{kg})$ in rats, through maintaining the hepatic antioxidant system, preserving the liver structure and counteracting the increase in serum ALT and AST levels as well as liver MDA accumulation (Sebai et al. 2015). It was also documented that CHEO could inhibit the activity of certain cytochrome P450 enzymes such as CYP3A4 (Ganzera et al. 2006) whose inhibition could safeguard against APAP hepatotoxicity (Wolf et al. 2007). With regard to the potential hepatoprotective effects of
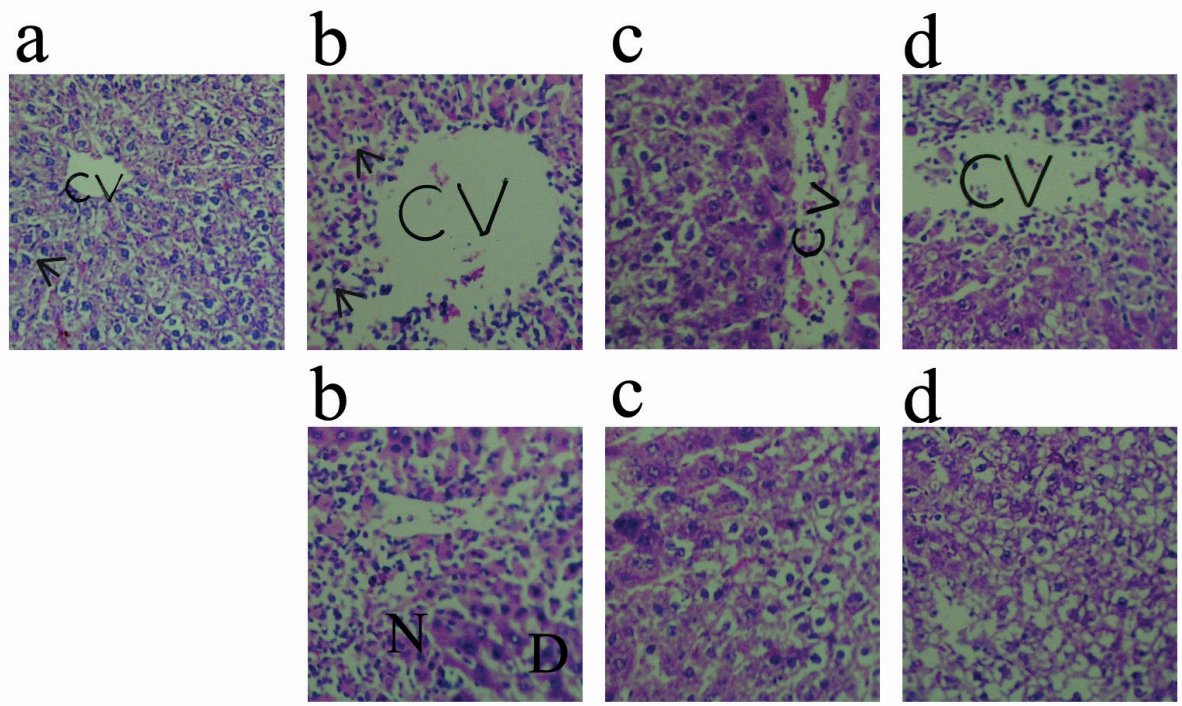

Figure 2 - Photomicrograph of the liver of rats assigned to four groups (a, b, c, d), $\mathbf{a}=$ control ( $1 \%$ Tween 80 , p.o. for 14 days), $\mathbf{b}=$ Toxic ( $1 \%$ Tween 80 , p.o. for 14 days) and APAP (acetaminophen $1 \mathrm{~g} / \mathrm{kg}$, p.o. on Day 14, twenty-four hours before blood sampling and liver dissection), $\mathbf{c}=$ CUEO (400 mg/kg/day, p.o. for 14 days $)+$ APAP, $\mathbf{d}=$ CHEO $(250 \mathrm{mg} / \mathrm{kg} /$ day, p.o. for 14 days) + APAP. H \& E Stain. Magnification set to be 40X. Whereas control rats (a) showed normal histological pattern of hepatocytes (arrow), APAP administration alone (b) caused massive centrolobular necrosis $(\mathrm{N})$, degeneration (D), inflammatory cells infiltration (arrows), hemorrhage and central vein dilation. Repeated doses of CUEO (c) were more hepatoprotective than CHEO (d) in APAP-intoxicated rats. Scores describing the extent of liver injury in each group are indicated in Table III. 
green cumin, it was demonstrated that rats which were chronically fed a diet mixed with cumin seeds ( $6 \%$ of the diet weight) and APAP $(500 \mathrm{mg} / \mathrm{kg}$ diet) exhibited an improvement in APAP-induced liver necrosis and increased serum ALT and AST levels (Elhabib et al. 2007). In the previous study, the possible role of oxidative stress in mediating chronic APAP hepatotoxicity was not investigated. The current findings revealed that CUEO did not affect evaluated markers of oxidative stress altered by acute APAP hepatotoxicity, although it abolished the increase in the serum levels of ALT and AST. Also, the results of histopathological examination indicated that prior CUEO treatment provided some protection against necrosis of hepatocytes and infiltration of inflammatory cells induced by acute APAP hepatotoxicity. In agreement with effects of CUEO on the liver function enzymes in response to drug-induced liver injury, chronic treatment (45 days) with the cumin powder suspension ameliorated ethanol-induced rise in the AST, ALP and gamma glutamyl transferase in rats (Aruna et al. 2005). CUEO was found to possess powerful anti-inflammatory activity via interfering with the expression of pro-inflammatory cytokines such as interleukin 1, interleukin 6 and nuclear factor kappa B (Wei et al. 2015), a transcription factor which regulates various aspects of inflammatory cascades, such as the expression of pro-inflammatory cytokines (Baldwin 1996, Hanada and Yoshimura 2002). It was also reported that CUEO suppressed lipopolysaccharide-induced activation of extracellular signal regulated kinase and c-Jun N-terminal kinase (Wei et al. 2015), which could play a role in APAP-induced cell death (Ghanem et al. 2016).

One unclear point that needs further investigation was the lack of any effects of CUEO and CHEO on the elevated MDA levels in the liver of APAP-treated rats. Instead, both CUEO and CHEO insignificantly aggravated the formation of MDA in the liver of APAP-intoxicated rats. Obviously, improving the liver protective antioxidant system has been widely reported to be accompanied with reduced MDA levels following acute APAP toxicity (El Morsy and Kamel 2015, Xie et al. 2016). In particular, CHEO had moderate improving effects on the reduced SOD activity and depleted GSH content in the livers of APAP-intoxicated rats, the case was opposite for acute APAP-induced liver MDA accumulation. This is in disagreement with the aforementioned study in which the Chamomilla recutita extract rescued APAP-lowered liver $\mathrm{Na}^{+} \mathrm{Ka}^{+}$ ATPase activity, a marker of membrane integrity, in rats (Gupta and Misra 2006). Importantly, the APAP dose in the previous study was one fifth of the standard APAP toxic dose used in the present study, and, therefore, this could not support the marked hepatoprotective effects of the chamomile extract, reported in Gupta and Misra (2006), against acute APAP hepatotoxicity particularly in the absence of histopathological studies. It is worth noting that constituents and their strength in the cumin or chamomile extract could be different from those isolated in their essential oils, and this could be one reason why CUEO and CHEO showed limited hepatoprotective effects in the present study.

\section{CONCLUSIONS}

The findings of this study suggest that CUEO and CHEO could offer some protection against acute APAP hepatotoxicity at $1 \mathrm{~g} / \mathrm{kg}$ body weight. CHEO seems to have partially counteracted acute APAP-induced liver injury through its antioxidant effects. In contrast, effects of CUEO were greater in preserving the liver histology, hindering migration of inflammatory cells between hepatocytes, and abolishing the rise in the liver function enzymes in APAP-intoxicated rats. Further studies are encouraged to determine whether previously reported anti-inflammatory properties of CUEO contribute to its hepatoprotective effects against APAP toxicity. 


\section{REFERENCES}

AGATONOVIC-KUSTRIN S, ORTAKAND DB, MORTON DW AND YUSOF AP. 2015. Rapid evaluation and comparison of natural products and antioxidant activity in calendula, feverfew, and German chamomile extracts. J Chromatogr A 1385: 103-110.

AHMED AE, HUSSEIN GI, LOH JP AND ABDELRAHMAN SZ. 1991. Studies on the mechanism of haloacetonitrile-induced gastrointestinal toxicity: interaction of dibromoacetonitrile with glutathione and glutathione-S-transferase in rats. J Biochem Mol Toxicol 6: $115-121$.

AL-MUSA H AND AL-HASHEM F. 2014. Hypoglycemic, hepato-renal and antioxidant potential effects of Chamomile recutita flowers ethanolic extract in streptozotocin-diabetic rats. Am J Pharmacol Toxicol 9: 1-12.

ALLAHGHADRI T, RASOOLI I, OWLIA P, NADOOSHAN MJ, GHAZANFARI T, TAGHIZADEH M AND ASTANEH SD. 2010. Antimicrobial property, antioxidant capacity, and cytotoxicity of essential oil from cumin produced in Iran. J Food Sci 75: H54-61.

ARUNA K, RUKKUMANI R, VARMA PS AND MENON VP. 2005. Therapeutic role of Cuminum cyminum on ethanol and thermally oxidized sunflower oil induced toxicity. Phytother Res 19: 416-421.

BALDWIN AS. 1996. The NF-kB and IkB proteins: new discoveries and insights. Annu Rev Immunol 14: 649-683.

CAVALIERI E, RIGO A, BONIFACIO M, CARCERERI DE PRATI A, GUARDALBEN E, BERGAMINI C, FATO R, PIZZOLO G, SUZUKI H AND VINANTE F. 2011. Proapoptotic activity of $\alpha$-bisabolol in preclinical models of primary human acute leukemia cells. J Transl Med 9: 45.

CHEN Q, GAN Z, ZHAO J, WANG Y, ZHANG S, LI J AND NI Y. 2014. In vitro comparison of antioxidant capacity of cumin (Cuminum cyminum L.) oils and their main components. LWT - Food Sci Technol 55: 632-637.

CONTRERAS-ZENTELLA ML AND HERNÁNDEZMUÑOZ R. 2016. Is liver enzyme release really associated with cell necrosis induced by oxidant stress? Oxid Med Cell Longev 2016: 3529149.

EL MORSY EM AND KAMEL R. 2015. Protective effect of artichoke leaf extract against paracetamol-induced hepatotoxicity in rats. Pharm Biol 53: 167-173.

ELHABIB EM, HOMEIDA MM AND ADAM SE. 2007. Effect of combined paracetamol and Cuminum cyminum or Nigella sativa use in Wistar rats. J Pharmacol Toxicol 2: 653-659.

FLEMMING M, KRAUS B, RASCLE A, JURGENLIEMK G, FUCHS S, FURST R AND HEILMANN J. 2015. Revisited anti-inflammatory activity of matricine in vitro: Comparison with chamazulene. Fitoterapia 106: 122-128.
GABE M. 1968. Histological Techniques. Paris: Masson Publisher, French, 1113 p.

GANZERA M, SCHNEIDER P AND STUPPNER H. 2006. Inhibitory effects of the essential oil of chamomile (Matricaria recutita L.) and its major constituents on human cytochrome P450 enzymes. Life Sci 78: 856-861.

GHANEM CI, PEREZ MJ, MANAUTOU JEAND MOTTINO AD. 2016. Acetaminophen from liver to brain: New insights into drug pharmacological action and toxicity. Pharmacol Res 109: 119-131.

GONZALEZ FJ. 2007. The 2006 Bernard B. Brodie Award Lecture CYP2E1. Drug Metab Dispos 35: 1-8.

GUNDUZ E, DURSUN R, ZENGIN Y, ICER M, DURGUN HM, KANICI A, KAPLAN I, ALABALIK U, GURBUZ H AND GULOGLU C. 2015. Lycium barbarum extract provides effective protection against paracetamol-induced acute hepatotoxicity in rats. Int J Clin Exp Med 8: 78987905.

GUPTA AK AND MISRA N. 2006. Hepatoprotective Activity of Aqueous Ethanolic Extract of Chamomile capitula in Paracetamol Intoxicated Albino Rats. Am J Pharmacol Toxicol 1: 17-20.

HAMZA RZ AND AL-HARBI MS. 2015. Amelioration of paracetamol hepatotoxicity and oxidative stress on mice liver with silymarin and Nigella sativa extract supplements. Asian Pac J Trop Biomed 5: 521-531.

HANADA T AND YOSHIMURA A. 2002. Regulation of cytokine signaling and inflammation. Cytokine Growth Factor Rev 13: 413-421.

HASANEIN P AND SHARIFI M. 2017. Effects of rosmarinic acid on acetaminophen-induced hepatotoxicity in male Wistar rats. Pharm Biol 55: 1809-1816.

JAGTAP AG AND PATIL PB. 2010. Antihyperglycemic activity and inhibition of advanced glycation end product formation by Cuminum cyminum in streptozotocin induced diabetic rats. Food Chem Toxicol 48: 2030-2036.

JIN SM, KIL HR, PARK K AND NOH CI. 2012. Gene expression in rat hearts following oral administration of a single hepatotoxic dose of acetaminophen. Yonsei Med J 53: 172-180.

KIRAN PM, RAJU AV AND RAO BG. 2012. Investigation of hepatoprotective activity of Cyathea gigantea (Wall. ex. Hook.) leaves against paracetamol-induced hepatotoxicity in rats. Asian Pac J Trop Biomed 2: 352-356.

KISAOGLU A, OZOGUL B, TURAN MI, YILMAZ I, DEMIRYILMAZ I, ATAMANALP SS, BAKAN E AND SULEYMAN H. 2014. Damage induced by paracetamol compared with $\mathrm{N}$-acetylcysteine. J Chin Med Assoc 77: 463-468.

KLEIN B, READ PAAND BABSON AL. 1960. Rapid method for the quantitative determination of serum alkaline phosphatase. Clin Chem 6: 269-275. 
KUMARI A AND KAKKAR P. 2012. Lupeol prevents acetaminophen-induced in vivo hepatotoxicity by altering the Bax/Bcl-2 and oxidative stress-mediated mitochondrial signaling cascade. Life Sci 90: 561-570.

LEE WM. 2013. Drug-induced acute liver failure. Clin Liver Dis 17: $575-586$.

LEUNG L. 2012. From ladder to platform: a new concept for pain management. J Prim Health Care 4: 254-258.

LOBENHOFER EK, BOORMAN GA, PHILLIPS KL, HEINLOTH AN, MALARKEY DE, BLACKSHEAR PE, HOULE C AND HURBAN P. 2006. Application of visualization tools to the analysis of histopathological data enhances biological insight and interpretation. Toxicol Pathol 34: 921-928.

MADRIGAL-SANTILLAN E, MADRIGAL-BUJAIDAR E, ALVAREZ-GONZALEZ I, SUMAYA-MARTINEZ MT, GUTIERREZ-SALINAS J, BAUTISTA M, MORALESGONZALEZ A, GONZALEZ-RUBIO MG, AGUILARFAISAL JL AND MORALES-GONZALEZ JA. 2014. Review of natural products with hepatoprotective effects. World J Gastroenterol 20: 14787-14804.

MARKLUND S AND MARKLUND G. 1974. Involvement of the superoxide anion radical in the autoxidation of pyrogallol and a convenient assay for superoxide dismutase. Eur J Biochem 47: 469-474.

MCKAY DL AND BLUMBERG JB. 2006. A review of the bioactivity and potential health benefits of chamomile tea (Matricaria recutita L.). Phytother Res 20: 519-530.

MIYANISHI K, HOKI T, TANAKA S AND KATO J. 2015. Prevention of hepatocellular carcinoma: Focusing on antioxidant therapy. World J Hepatol 7: 593-599.

MLADENOVIC D, RADOSAVLJEVIC T, NINKOVIC M, VUCEVIC D, JESIC-VUKICEVIC R AND TODOROVIC V. 2009. Liver antioxidant capacity in the early phase of acute paracetamol-induced liver injury in mice. Food Chem Toxicol 47: 866-870.

MNIF S AND AIFA S. 2015. Cumin (Cuminum cyminum L.) from traditional uses to potential biomedical applications. Chem Biodivers 12: 733-742.

PATIL SB, TAKALIKAR SS, JOGLEKAR MM, HALDAVNEKAR VS AND ARVINDEKAR AU. 2013. Insulinotropic and $\beta$-cell protective action of cuminaldehyde, cuminol and an inhibitor isolated from Cuminum cyminum in streptozotocin-induced diabetic rats. Br J Nutr 110: 1434-1443.

REITMAN S AND FRANKEL S. 1957. A colorimetric method for the determination of serum glutamic oxalacetic and glutamic pyruvic transaminases. Am J Clin Pathol 28: 56-63.

ROCHA NF, OLIVEIRA GV, ARAUJO FY, RIOS ER, CARVALHO AM, VASCONCELOS LF, MACEDO DS, SOARES PM, SOUSA DP AND SOUSA FC. 2011. $(-)-\alpha$-Bisabolol-induced gastroprotection is associated with reduction in lipid peroxidation, superoxide dismutase activity and neutrophil migration. Eur J Pharm Sci 44: 455-461.

ROYAL PHARMACEUTICAL SOCIETY. 2015. Nervous System: Pain. In: British National Formulary 70. London: BMJ Group, Pharmaceutical Press, UK, p. 354-383.

RUFINO AT, RIBEIRO M, JUDAS F, SALGUEIRO L, LOPES MC, CAVALEIRO C AND MENDES AF. 2014. Anti-inflammatory and chondroprotective activity of (+)- $\alpha$-pinene: Structural and enantiomeric selectivity. J Nat Prod 77: 264-269.

SEBAI H, JABRI MA, SOULI A, HOSNI K, RTIBI K, TEBOURBI O, EL-BENNA J AND SAKLY M. 2015. Chemical composition, antioxidant properties and hepatoprotective effects of chamomile (Matricaria recutita L.) decoction extract against alcohol-induced oxidative stress in rat. Gen Physiol Biophys 34: 263-275.

SINGH D, CHO WC AND UPADHYAY G. 2016. Druginduced liver toxicity and prevention by herbal antioxidants: An Overview. Front Physiol 6: 363.

SORG DA AND BUCKNER B. 1964. A Simple Method of Obtaining Venous Blood from Small Laboratory Animals. Proc Soc Exp Biol Med 115: 1131-1132.

SRIVASTAVA JK, SHANKAR E AND GUPTA S. 2010. Chamomile: A herbal medicine of the past with bright future. Mol Med Rep 3: 895-901.

TOMY MJ, DILEEP KV, PRASANTH S, PREETHIDAN DS, SABU A, SADASIVAN C AND HARIDAS M. 2014. Cuminaldehyde as a lipoxygenase inhibitor: in vitro and in silico validation. Appl Biochem Biotechnol 174: 388-397.

UCHIYAMA M AND MIHARA M. 1978. Determination of malonaldehyde precursor in tissues by thiobarbituric acid test. Anal Biochem 86: 271-278.

VINHOLES J, RUDNITSKAYA A, GONCALVES P, MARTEL F, COIMBRA MA AND ROCHA SM. 2014. Hepatoprotection of sesquiterpenoids: A quantitative structure-activity relationship (QSAR) approach. Food Chem 146: 78-84.

WEI J, ZHANG X, BI Y, MIAO R, ZHANG Z AND SU H. 2015. Anti-Inflammatory Effects of Cumin Essential Oil by Blocking JNK, ERK, and NF-kB Signaling Pathways in LPS-Stimulated RAW 264.7 Cells. Evid Based Complement Altern Med 2015: 474509.

WEICHSELBAUM TE. 1946. An accurate and rapid method for the determination of proteins in small amounts of blood serum and plasma. Am J Clin Pathol 10: 40-49.

WEYDERT CJ AND CULLEN JJ. 2010. Measurement of superoxide dismutase, catalase and glutathione peroxidase in cultured cells and tissue. Nat Protoc 5: 51-66.

WHITCOMB DC AND BLOCK GD. 1994. Association of acetaminophen hepatotoxicity with fasting and ethanol use. JAMA 272: 1845-1850. 
WOLF KK ET AL. 2007. Role of CYP3A and CYP2E1 in alcohol-mediated increases in acetaminophen hepatotoxicity: Comparison of wild-type and Cyp2e1(-/-) mice. Drug Metab Dispos 35: 1223-1231.

WOOLBRIGHT BL AND JAESCHKE H. 2017. Role of the Inflammasome in Acetaminophen-induced Liver Injury and Acute Liver Failure. J Hepatol 66: 836-848.
XIE W, WANG M, CHEN C, ZHANG X AND MELZIG MF. 2016. Hepatoprotective effect of isoquercitrin against acetaminophen-induced liver injury. Life Sci 152: 180-189.

\section{SUPPLEMENTARY MATERIAL}

Analyses S1-S2. 